$$
\begin{array}{r}
\text { Pontifícia Universidade Católica } \\
\text { do Rio de Janeiro }
\end{array}
$$

Sonia Isabel Fabris Campos

\title{
Entre os muros da escola: a percepção da violência familiar em narrativas de educadores
}

\section{Tese de Doutorado}

Tese apresentada ao Programa de Pós-graduação em Letras do Departamento de Letras da PUC-Rio como parte dos requisitos parciais para obtenção do título de Doutor em Letras.

Orientadora: Profa. Liliana Cabral Bastos

Co-orientadora: Profa. Maria do Carmo Leite de Oliveira 


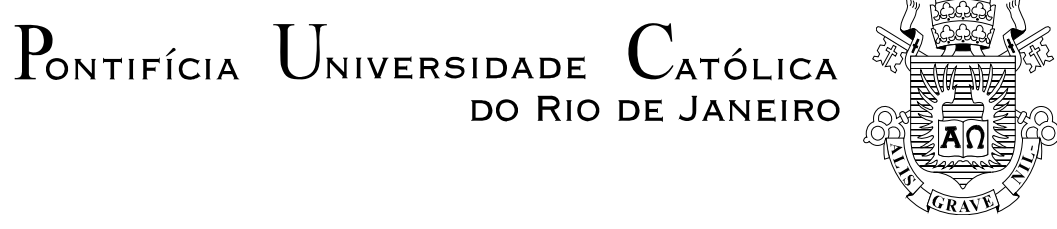

Sonia Isabel Fabris Campos

\title{
Entre os muros da escola: a percepção da violência familiar em narrativas de educadores
}

Tese apresentada como requisito parcial para obtenção do grau de Doutor pelo Programa de Pós-Graduação em Letras do Departamento de Letras do Centro de Teologia e Ciências Humanas da PUC-Rio. Aprovada pela Comissão Examinadora abaixo assinada.

\author{
Profa. Liliana Cabral Bastos \\ Orientadora \\ Departamento de Letras - PUC-Rio
}

Profa. Maria do Carmo Leite de Oliveira

Co-Orientadora

Departamento de Letras - PUC-Rio

Profa. Maria das Graças Dias Pereira

Departamento de Letras - PUC-Rio

Profa. Inés Kayon de Miller Departamento de Letras - PUC-Rio

Prof. Luiz Paulo da Moita Lopes

UFRJ

Profa. Maria Claudia Pereira Coelho

UERJ

Profa. Denise Berruezo Portinari Coordenadora Setorial do Centro de Teologia

e Ciências Humanas - PUC-Rio

Rio de Janeiro, 08 de abril de 2011. 
Todos os direitos reservados. É proibida a reprodução total ou parcial do trabalho sem autorização da universidade, da autora e da orientadora.

\section{Sonia Isabel Fabris Campos}

Possui graduação em Língua Inglesa e Literaturas da lìngua Inglesa pela Universidade Federal do Espírito Santo (1975), Diploma for Overseas Teachers of English (DOTE) da Universidade de Cambridge, RSA (1994), Especialização em Didática do Ensino Superior da Faculdade de Ciências e Letras de Macaé em convênio com a UERJ (UERJ-FAFiMA), Especialização em Língua Inglesa pela Pontifícia Universidade Católica do Rio de Janeiro (2002) e mestrado em Linguísitca Aplicada pela Universidade Federal do Rio de Janeiro (2006). Tem experiência ensino da língua inglesa em escolas particulares, na escola pública, Universidade Federal do Espírito Santo, cursos de língua inglesa, treinamento de professores, coordenação acadêmica e orientação pedagógica do ensino de inglês como língua estrangeira e de educação infantil. Sua pesquisa privilegia o ensino de língua inglesa como língua franca, o posicionamento dos professores de língua na atualidade. Doutora em Estudos da Linguagem pela Pontifícia Universidade Católica do Rio de Janeiro. No doutorado realizou pesquisa sobre a percepção da violência intrafamiliar e o sofrimento dos alunos nas narrativas dos educadores de escola pública e particular do Rio de Janeiro.

Ficha Catalográfica

Campos, Sonia Isabel Fabris

Entre os muros da escola: a percepção da violência intrafamiliar e do sofrimento em narrativas de educadores / Sonia Isabel Fabris Campos; orientadora: Liliana Cabral Bastos; co-orientadora: Maria do Carmo Leite de Oliveira. - 2011.

270 f. ; $30 \mathrm{~cm}$

Tese (doutorado) - Pontifícia Universidade Católica do Rio de Janeiro, Departamento de Letras, 2011.

Inclui bibliografia

1. Letras - Teses. 2. Narrativas. 3. Posicionamento. 4. Identidade. 5. Violência. 6. Escola. 7. Família. I. Bastos, Liliana Cabral. II. Oliveira, Maria do Carmo Leite de. III. Pontifícia Universidade Católica do Rio de Janeiro. Departamento de Letras. IV. Título. 
Aos meus filhos, minha inspiração maior e aos meus pais, cujo desejo está aqui concretizado. 


\section{Agradecimentos}

À minha orientadora, Professora Liliana Cabral Bastos, pela aposta, companheirismo, incentivo e preciosos, sábios e indispensáveis ensinamentos.

À minha co-orientadora, Professora Maria do Carmo Leite de Oliveira, querida parceira, generosa e grande mestra. Agradeço a sua disponibilidade e carinho.

Ao Professor Doutor Luiz Paulo da Moita Lopes, agora compondo a minha banca para questionar, opinar e avaliar um trabalho pelo qual é co-responsável, por uma simples razão, foi o meu instigador intelectual.

À querida Professora Doutora Branca Falabella por me encorajar com a sua dedicação intelectual, impecável.

À Dra Raquel Niskier, agradeço imensamente por ter me recebido e me ouvido e, principalmente, por ter me ajudado a fazer a escolha mais acertada.

À Professora Doutora Inés Miller, minha companheira de longa jornada, que me ajudou a plantar lá atrás a semente, nos encontros da Prática Exploratória e depois no curso de Especialização da PUC.

Ao Professor Doutor Ralph Ings Bannell, que com suas contribuições críticas, fundamentais me levou a indagar e a debruçar sobre minhas incertezas de uma forma instigante.

À Professora Doutora Maria das Graças, uma incentivadora de delicadeza ímpar.

À Professora Doutora Maria Cláudia Coelho por compor esta banca e por ter sido também fonte de inspiração nas minhas indagações sociológicas.

À Profa. Dra. Helena Martins pela paixão que transmitiu e pelos inesquecíveis.

À psicanalista, Dra Tereza Nazar, por ter-me permitido o exercício da perseverança e mais ainda, muito mais, por trilhar comigo os caminhos para a realização desse meu precioso desejo.

Ao meu marido, Antonio Carlos, pela compreensão e apoio.

Aos meus queridos filhos, Ligia, Vitor, Antonio e João Pedro, por todos os pequenos gestos de incentivo e de apoio, pelo companheirismo, carinho e por tudo aquilo que nas palavras não cabem.

Ao meu filho, João Pedro, pela grande contribuição e dedicação na formatação da tese.

Ao meu genro, Guilherme Leite Gonçalves, que contribuiu com a sua sabedoria e com pequenos gestos que se tornaram grandes, sem que o soubesse. 
À querida Ana Salek que me estimulou com a sua curiosidade e a poesia permanente na sua vida e na sua afetividade.

Aos meus irmãos que, com a sua indispensável compreensão, me deram suporte, apoio e tranqüilidade e torceram para que obtivesse êxito nesse projeto.

A Conceição pelo incansável apoio.

A Fabienne pela valiosa ajuda que me ofereceu de maneira generosa e acolhedora.

A Rosangela, amiga querida de tantos anos, pelo incansável apoio e indispensável e generoso afeto.

A Valéria amiga e parceira de tantos projetos, tão presente nas horas essenciais.

À amiga Andrea, pelas mensagens encorajadoras e pela amizade tão cara.

À prima-irmã, Angélica, pela presença amiga e estímulo constante.

Às minhas amigas, Maria Tereza, Dora, Ana Cristina, Marilda, Lucia agradeço a paciência, a compreensão, o carinho e a presença na distância.

A Sandra Peralta, minha querida amiga, que torceu tanto por mim, carinhosa e generosamente.

Às queridas colegas, parceiras e incentivadoras: Paula Castro, Cláudia Ruas, Cristina Carvalho, Loana, Ana Paula Lemos, Soraya, Carol, Vivi. Agradeço, sobretudo, a compreensão e solidariedade.

Às professoras, colegas, amigas, Vânia D'Angelo, Luciana, Anna Paula, Cristiane, Erika, há tantos anos compartilhando as nossas inspirações, os nossos ideais e as nossas lutas diárias. Obrigada pela cooperação e estímulo.

À Escola Parque, pelo apoio e incentivo que nunca faltaram.

Às professoras Deborah e Magaly, queridas amigas. Agradeço a dedicação, indispensável para que pudesse me dedicar ao meu trabalho.

A Daniele e Chiquinha, agradeço pela mão sempre estendida e indispensável colaboração.

Às amigas de grupo de pesquisa Márcia Frias, Sonia Rosas, Liana, Talita, Daniella, Clarissa, Ana Tereza, Julio por compartilharem seu conhecimento, suas conquistas. Agradeço, acima de tudo, pelas preciosas contribuições no nosso grupo de pesquisa e fora dele.

Aos educadores que participaram desta pesquisa e que gentil e generosamente concederam seu tempo, prestando valiosas contribuições sem as quais este estudo não teria sido o que foi. 


\section{Resumo}

Fabris Campos, Sonia Isabel; Bastos, Liliana Cabral (Orientadora); Oliveira, Maria do Carmo Leite de (Co-orientadora). Entre os muros da escola: a percepção da violência familiar em narrativas de educadores. Rio de Janeiro, 2011, 270p. Tese de Doutorado - Departamento de Letras, Estudos da Linguagem, Pontifícia Universidade Católica do Rio de Janeiro.

Esta pesquisa tem como objeto de estudo a violência familiar que atravessa os muros da escola. Busca-se analisar as percepções de educadores de escolas públicas e privadas, que emergem em narrativas no contexto de entrevistas de pesquisa sobre a violência familiar, o papel da escola e do Estado e do educador no tratamento desse tipo de violência. A análise é feita à luz de estudos sobre violência no Brasil e sobre narrativa, aqui entendida como uma prática discursiva, por meio da qual os narradores constroem sentidos sobre o mundo social e se envolvem na performance de quem são. Os resultados da análise revelam que tipos de violência são considerados reportáveis e que razões são atribuídas para sua ocorrência; como os narradores/entrevistados se posicionam no papel de entrevistado, como pessoas em sua relação com a sociedade, ali representada pela família, escola, Estado, mídia e, também, os como atores monitoram sua performance, orientados para uma audiência projetada. A pesquisa enfatiza a necessidade de um papel mais atuante da Escola na mediação dos conflitos e do Estado na sua solução, assim como uma reformulação dos programas de formação de professor, buscando uma melhor capacitação desse profissional para lidar com os problemas que os alunos e as famílias enfrentam na atualidade.

\section{Palavras-chave}

Narrativas; posicionamento; identidade; violência; escola; família. 


\section{Abstract}

Fabris Campos, Sonia Isabel; Bastos, Liliana Cabral (Advisor); Oliveira, Maria do Carmo Leite de (Co-advisor). Inside the school walls: the perception of violence in the family in educators' narratives. Rio de Janeiro, 2011, 270p. PhD Thesis. Departamento de Letras, Estudos da Linguagem, Pontifícia Universidade Católica do Rio de Janeiro.

This research has as its object of study the form of domestic violence which crosses the school gates from the perspective of the teachers and education professionals at state and private schools. It aims at analysing their perceptions of violence within the family, as well as of the role of schools, the State, and the teachers and education professionals, with regard to this type of violence. The analysis is done within the context of violence studies in Brazil and also of narrative studies, regarded as discursive practices through which narrators make sense of their social world and perform who they are situationally. The findings in the analysis refer to (i) the types of violence which are considered reportable and what reasons the speakers attribute to them; (ii) how the narrators position themselves as a participant in the interview, as a person vis-à-vis the society, represented in the event by the family, the State, the school, the media and, iii) also, as actors who constantly monitor their performance, in view of their projected audience. This research emphasises the necessity of a more active role played by the school as a conflict mediator, and of the State as being responsible for providing solutions to the problems the schools face. It points out the utmost importance of redesigning teaching preparation courses, which should enable teachers to deal with the problems the students and their families are facing today.

\section{Keywords}

Narratives; positioning; identity; violence; school; family. 


\section{Lista de Abreviaturas}

CONDECA: Conselho Estadual da Criança e do Adolescente

CRAMI: Centro Regional de Atenção aos Maus Tratos na Infância

ECA: Estatutos da Criança e do Adolescente

OMS: Organização Mundial de Saúde 


\section{Convenções para transcrições}

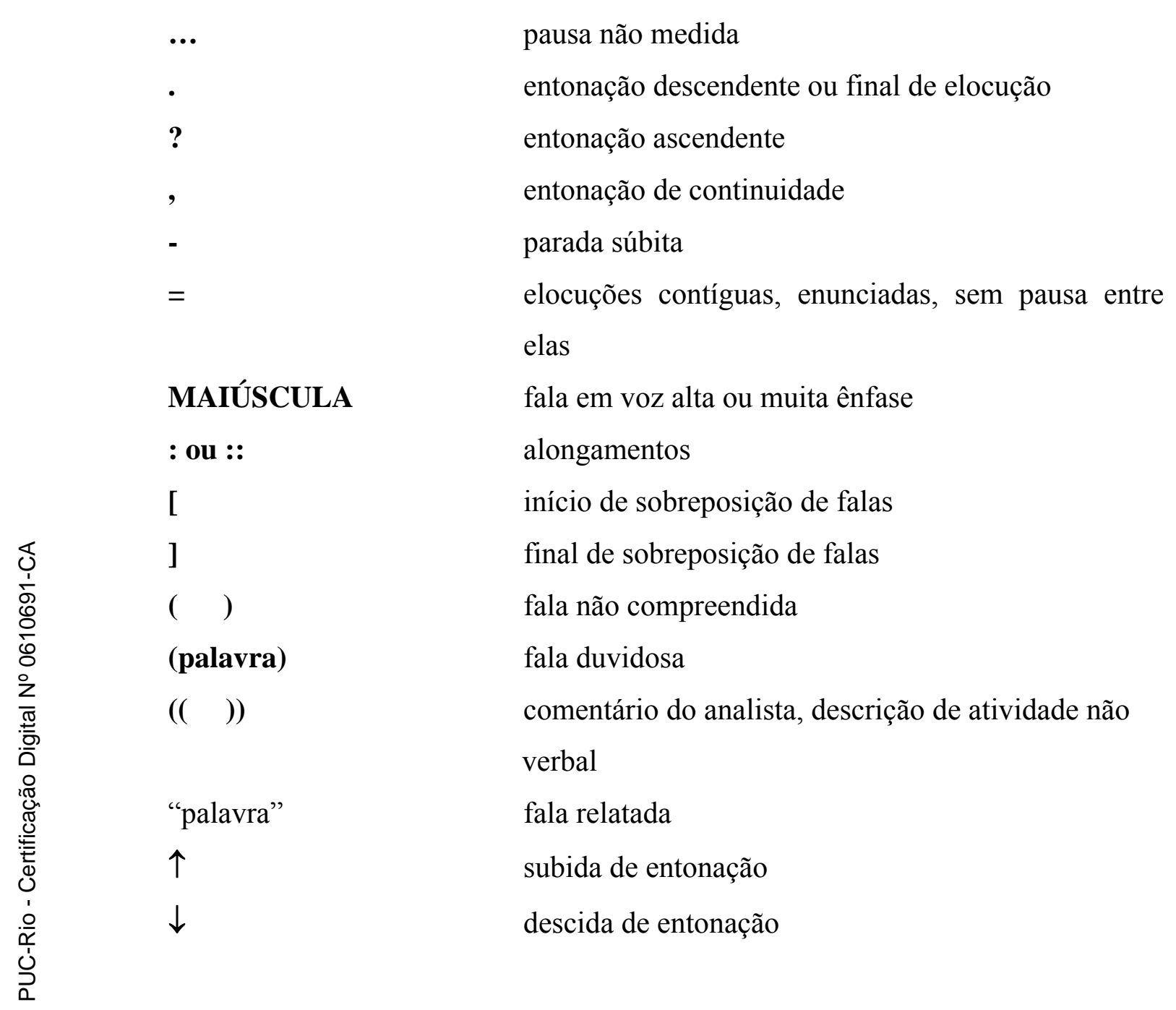




\section{Sumário}

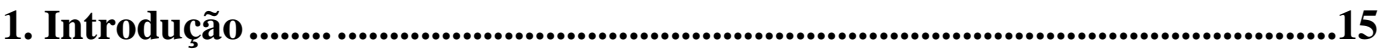

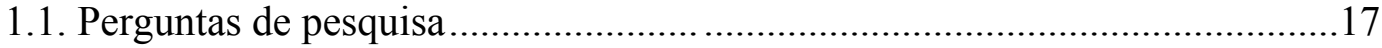

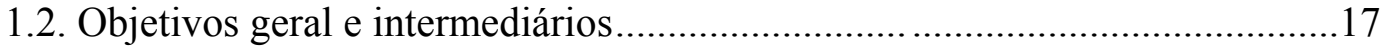

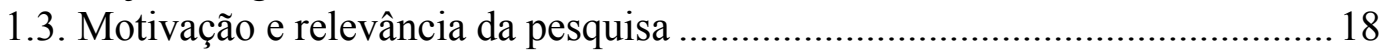

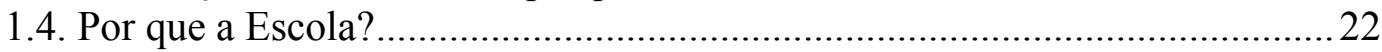

2. Contemporaneidade e Violência .................................................................... 26

2.1. A virada sociocultural e a escola na contemporaneidade .............................2 27

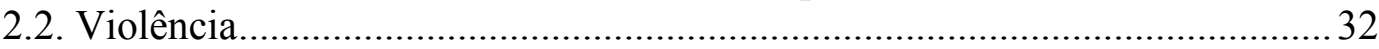

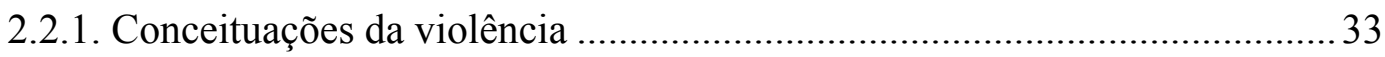

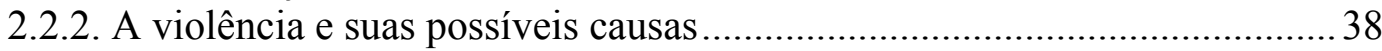

2.2.3. A violência na família: suas formas e seus alvos ....................................... 40

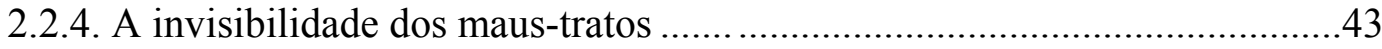

2.2.5. Os mecanismos de controle da violência: o Estatuto da Criança

e do Adolescente, o Conselho Tutelar e a Cartilha de Bullying:..........................49

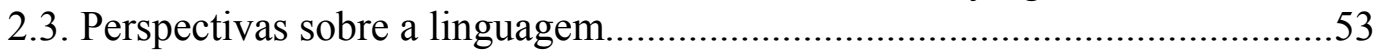

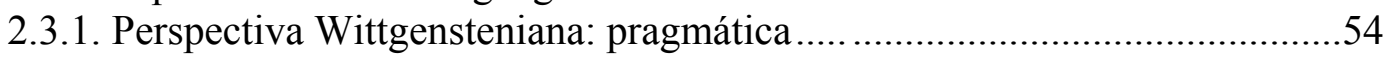

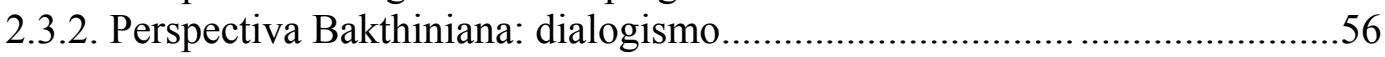

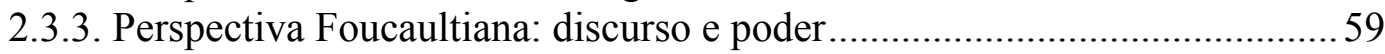

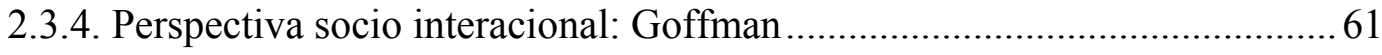

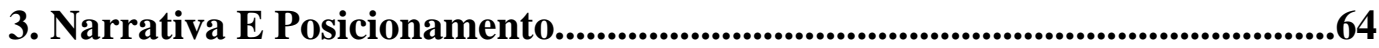

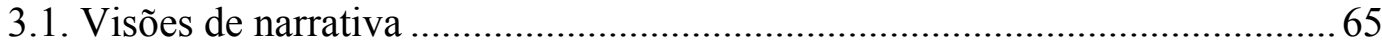

3.1.1. O modelo laboviano e narrativa como co-construção da vida social .......... 65

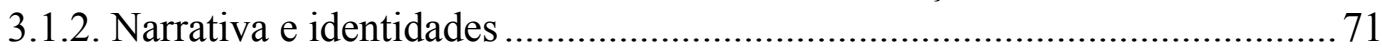

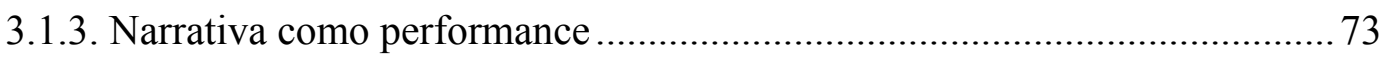

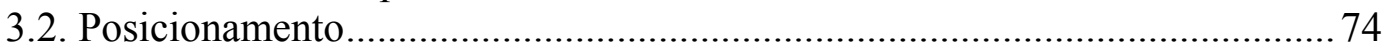

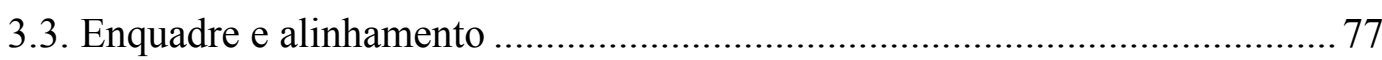

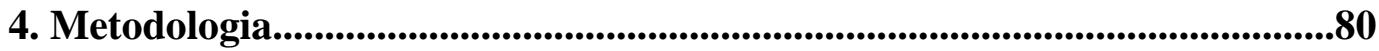

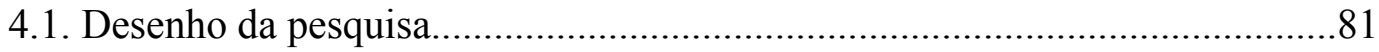

4.2. A entrevista como método de geração de dados........................................... 82

4.3. Geração de dados, participantes e universo da pesquisa .............................. 89

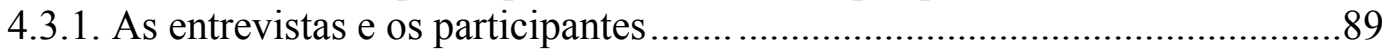

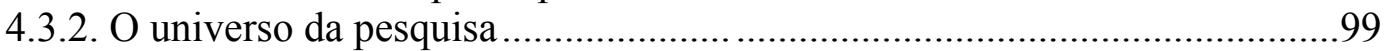

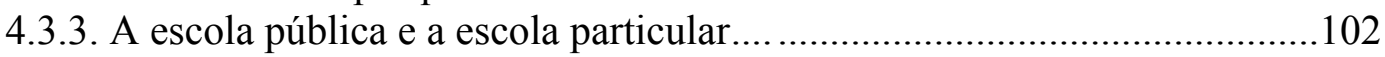

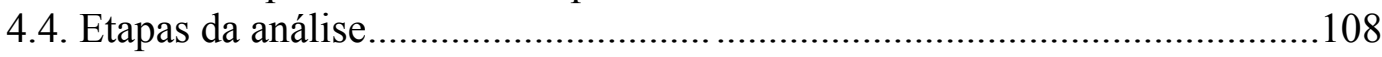

5. A Violência na fala dos educadores.............................................................109

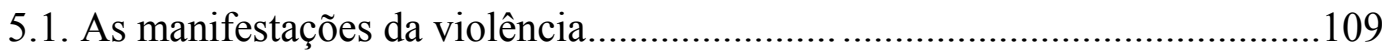

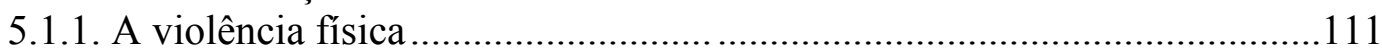

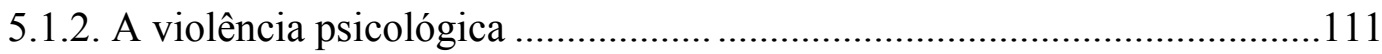

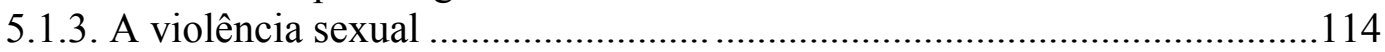

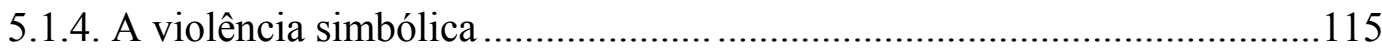

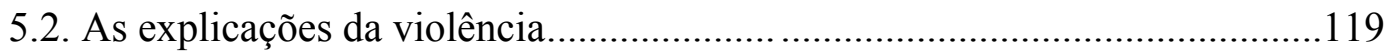


5.2.1. O modelo de sociedade

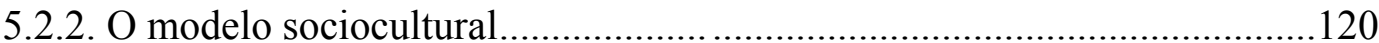

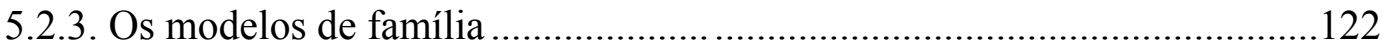

6. Percepção da violência em performances narrativas.....................................126

6.1. Posicionamento dos narradores na interação com a entrevistadora ............. 126

6.2. Posicionamento e identidade em narrativas de violência...............................150

6.2.1. Posicionamento e identidade profissional...............................................151

6.2.2. Posicionamento: alunos, escola, família e sociedade ................................ 169

6.3. Posicionamento: “quem sou eu para a minha audiência?’............................190

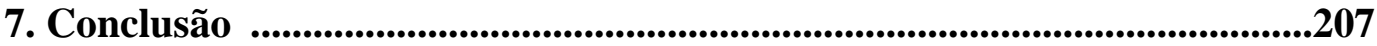

8. Referências bibliográficas..................................................................... 211

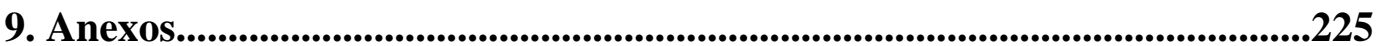

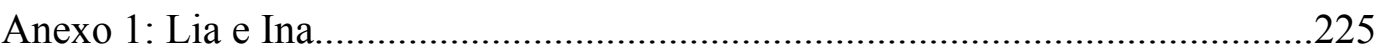

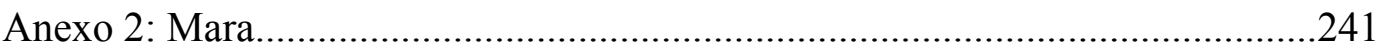

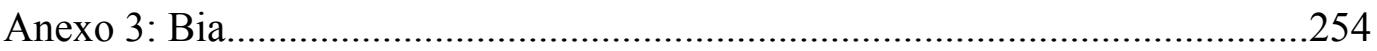

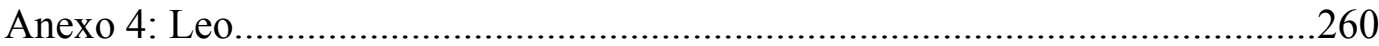


(...) é esta sensibilidade dolorosa que se comove com misérias que às vezes mesmo os que as carregam desconhecem, esta sensibilidade que é uma antena delicadíssima, captando pedaços de todas as dores do mundo, e que me fará morrer de dores que não são minhas.

Newton Braga (1911-1962), Fraternidade 


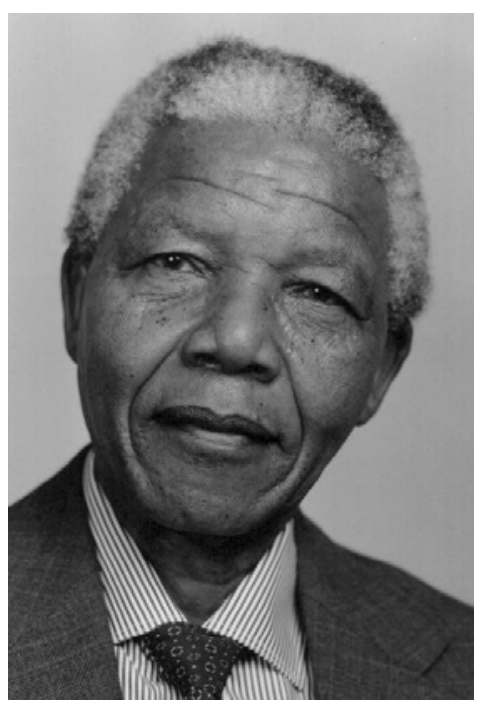

O século vinte será lembrado como um século marcado pela violência. Em uma escala jamais vista e nunca antes possível na história da humanidade, ele nos oprime com seu legado de destruição em massa, de violência imposta. Mas esse legado resultado de novas tecnologias a serviço de ideologias de ódio - não é o único que carregamos, nem que devemos enfrentar. Menos visível, mais ainda mais disseminado, é o legado do sofrimento individual diário. É a dor das crianças que sofrem abusos provenientes das pessoas que deveriam protegê-las, mulheres feridas ou humilhadas por parceiros violentos, pessoas idosas maltratadas por aqueles que são os responsáveis pelos seus cuidados, jovens oprimidos por outros jovens e pessoas de todas as idades que infligem violência contra si próprias. Este sofrimento - e há muitos outros exemplos que eu poderia citar - é um legado que se reproduz quando novas gerações aprendem com a violência de gerações passadas, quando as vítimas aprendem com seus agressores e quando se permite que se mantenham as condições sociais que nutrem a violência. Nenhum país, nenhuma cidade, nenhuma comunidade está imune à violência, mas, também, não estamos impotentes diante dela.

$\mathrm{Na}$ ausência de democracia, respeito pelos direitos humanos e um bom governo, a violência prospera. Freqüentemente conversamos sobre como uma "cultura de violência" pode criar raízes. Isso, de fato, é uma verdade. Como um sul-africano que vivenciou o apartheid e está vivendo suas conseqüências, tenho visto e experimentado isto. Também é verdade que os padrões de violência são mais difusos e difundidos nas sociedades em que as autoridades endossam o uso da violência por meio de suas próprias ações. Em muitas sociedades, a violência é tão dominante que frustra as esperanças de desenvolvimento econômico e social. Não podemos deixar que isto continue.

Muitos dos que convivem com a violência dia após dia assumem que ela é parte intrínseca da condição humana, mas isto não é verdade. A violência pode ser evitada. As culturas violentas podem ser modificadas.

Nós devemos às nossas crianças - os cidadãos mais vulneráveis em qualquer sociedade - uma vida livre de violência e medo. A fim de assegurar isto, devemos manter-nos incansáveis em nossos esforços não apenas para alcançar a paz, a justiça e a prosperidade para os países, mas também para as comunidades e membros da mesma família. Devemos dirigir nossa atenção para as raízes da violência. Somente assim, transformaremos o legado do século passado de um fardo opressor em um aviso de alerta.

Nelson Mandela ${ }^{1}$

\footnotetext{
${ }^{1}$ Texto retirado (e adaptado) do prefácio do $1^{\circ}$. Relatório Mundial de Saúde da Organização Mundial de Saúde, publicado em 2002, site http://www.opas.org.br/cedoc/hpp/ml03/0329.pdf, acesso em 12 de janeiro de 2011.
} 